\title{
Herbisit Glifosatın Daphnia magna Üzerine Akut Toksisitesi*
}

\section{Zeynep SARIGÜL ${ }^{1}$}

Geliş Tarihi: 04.11.2008

\author{
Süleyman BEKCAN ${ }^{2}$
}

Kabul Tarihi:06.07.2009

Öz: Bu çalışmada, Daphnia magna üzerinde, \%48 glifosat içeren Roundup isimli herbisitin, 24 ve 48 saatlik ortalama öldürücü konsantrasyonları $\left(\mathrm{LC}_{50}\right)$ saptanmıştır. Deneme statik biyodeney yöntemi ile 2 seride yürütülmüş, beş farklı konsantrasyon $(0,0115 ; 0,018 ; 0,021 ; 0,028 ; 0,032)$ ve bir kontrol grubu kullanılmıştır. Deney süresi 24 ve 48 saattir. LC $_{50}$ değerleri probit analiz yöntemine göre hesaplanmıştır. Sonuç olarak glifosatın 24 saatte Daphnia magnaların \% 50'sini öldüren konsantrasyon 0,019 mg/L (\%95 güven aralığında $=0,012 \mathrm{mg} / \mathrm{L}-0,024 \mathrm{mg} / \mathrm{L}$ ) , 48 saatte $\% 50$ 'sini öldüren konsantrasyon ise $0,012 \mathrm{mg} / \mathrm{L}$ (\%95 güven aralığında $=0,001 \mathrm{mg} / \mathrm{L}-0,016 \mathrm{mg} / \mathrm{L}$ ) olarak saptanmıştır.

Anahtar Kelimeler: Daphnia, herbisit, glifosat, akut toksisite, biyodeney

\section{Acute Toxicity of The Herbicide Glyphosate on Daphnia magna}

Abstract: In this study, median lethal concentrations $\left(\mathrm{LC}_{50}\right)$ of herbicide Roundup, which contains \%48 glyphosate ,on Daphnia magna for 24 an 48 hours were determined. The experiment has been conducted with the method of static bioassay on two series, five different concentrations $(0.0115 ; 0.018 ; 0.021 ; 0.028 ; 0.032)$ and one control group have been used. The period of the experiment is 24 and 48 hours. As to the LC ${ }_{50}$ values have been calculated with the method of probit analysis. Experimental results showed that; the concentration of the glyphosate which killed $50 \%$ of Daphnia magna was $0.019 \mathrm{mg} / \mathrm{L}(\% 95$ confidence interval=0.012 mg/L$0.024 \mathrm{mg} / \mathrm{L}$ ) for 24 hours, but the the concentration of the glyphosate which killed $50 \%$ of Daphnia magna was $0.012 \mathrm{mg} / \mathrm{L}$ (\%95 confidence interval=0.001 mg/L-0.016 mg/L) for 48 hours.

Key Words: Daphnia, herbicide, glyphosate, acute toxicity, bioassay

\section{Giriş}

Herbisitler günümüzde birçok ülkede kullanılmaktadır. Gelişmiş ülkelerde kullanım azalma göstermesine rağmen, az gelişmiş ve gelişmekte olan ülkelerde hala yüksek oranda kullanılmaktadır (IARC 1977). Herbisitler yabancı otlara karşı toksik olan pestisitlerdir. Sulama kanallarının yabancı otlardan korunmasında, nehir, göl kenarlarında, kamış ve sazlıkların kurutulmasında, fabrika ve demiryollarının kenarlarındaki yabancı otların imhasında kullanılmaktadır. Yeni bir herbisit olarak 1971 yılında tanıtılan glifosat, 1974 yılında Amerika'da piyasaya sürülmüştür (Baird ve ark. 1971).

Glifosat, karasal ve akvatik ortamlarda bitki kontrolünde yaygın bir şekilde kullanılan seçici olmayan geniş spektrumlu bir herbisittir (Alberdi ve ark. 1996).
$\mathrm{C}_{3} \mathrm{H}_{8} \mathrm{NO}_{5} \mathrm{P} \quad\left(\mathrm{HO}-\mathrm{COH}_{2} \mathrm{NHCH}_{2} \mathrm{P}=\mathrm{O} \quad(\mathrm{OH})_{2}\right)$ formülüne sahip, renksiz katı kristaller halindedir (Knuuttila ve Knuuttila 1979).

Glifosat tüm sucul flora ve fauna üzerinde toksikolojik özellikler sergileyebilmektedir (Goldsborough ve Beck 1989). Laboratuvar koşullarında steril sularda aşırı bir stabiliteye sahipken, sahadaki sucul ortamlarda hızlı bir dağılıma sahiptir (Bronstad ve Friestad 1985).

Glifosat 1976 döneminde ABD'de başlıca tarım ürünlerinde, arpa, buğday, mısır, soya fasülyesinde kullanılmış, 1980 yılında 50'nin üzerindeki tarım ürünleri ile endüstri bölgelerinde kullanılmaya başlanmıştır (Monsanto 1980).

\footnotetext{
* Yüksek Lisans Tezinden hazırlanmıştır.

${ }^{1}$ Tarım ve Köyişleri Bakanlığı

${ }^{2}$ Ankara Üniv. Ziraat Fak. Su Ürünleri Bölümü-Ankara
} 
Zehirli kimyasallara karşı en hassas gruplardan biri olduğu ve lentik (durgun su) besin zincirinde merkezi bir konumda olduğu için zooplanktonlar ekotoksikolojik testlerde sıklıkla kullanılmaktadır. Zooplanktonların toksisiteye karşı verdikleri tepkilerle, ekosistem üzerindeki göreceli etkiler hakkında bir bütün olarak bilgi sağladıkları düşünülmektedir (Hanazato 2001).

Akvatik ekosistemlerde Daphnia'ların özellikle ikincil üretim olarak besin zincirinin ikinci halkasını oluşturmaları ve beslenmeleri bu üretime bağlı organizmalar, balıklar vb. açıdan büyük önem taşımaktadır.

Daphnia spp. ile yapılan standart testler resmi olarak milletlerarası \{( USEPA) Amerika Çevre Koruma Teşkilatı, (EEC) Avrupa Ekonomik Topluluğu ve (OECD) Ekonomik ve Gelişme Teşkilatı kuruluşlar tarafından tatlısu omurgasızları olarak uygun bulunmuştur. Hemen hemen her ülkede düzenleyici testler için kullanılmaları önerilmektedir (Persoone ve Janssen 1993).

Herbisitlerin ekosistem ve hayvanlar üzerindeki toksisitesine ilişkin birçok bilimsel deneyler yapılmasına (Medina ve ark. 1994, Piska ve Waghray 1997) karşın, akvatik ekosistem üzerindeki toksisitesi hakkındaki bilgiler oldukça sınırlıdır.

$\mathrm{Bu}$ çalışmada glifosat herbisitin Daphnia magna üzerine akut toksisitesinin belirlenmesi amaçlanmıştır. Elde edilen bulgular, bu herbisitin akvatik canlılar üzerindeki toksisitesine ilişkin veri tabanının genişletilmesinde katkıda bulunması açısından önemli olacaktır.

\section{Materyal ve Yöntem}

Bu çalışmada Daphnia magna üzerine herbisit Glifosatın 24 ve 48 saatlik akut toksisitesi incelenmiştir. Deneme materyali olarak Kepez Su Ürünleri Araştırma Enstitüsünden sağlanan Daphnia magnalar kullanılmıştır. Deney organizması olarak, öncelikle yumurtalı bireyler seçilerek ayrı bir ortama alınmış ve yumurtlama sağlandıktan sonra yavrular 5 gün süreyle aynı besleme programına (alg+maya) tabi tutulduktan sonra denemede kullanılmışlardır. Denemede Kullanılan Toksik Madde Ticari adı Roundup Ultra olan herbisittir.

Deneme A. Ü. Ziraat Fakültesi Su Ürünleri Bölümü laboratuvarlarında gerçekleştirilmiştir.Deneyler süresince yemleme yapılmamıştır. Deneylerde, deney çözeltisi ile kimyasal reaksiyona girmeyen malzemeden yapılmış, orta büyüklükte, geniş ağızlı, 150 ml'lik cam kavanozlar, pipetler, mikroskop ve diğer laboratuvar gereçlerinden yararlanılmıştır.
Her deney kabında gerekli toksik madde konsantrasyonunu içeren $100 \mathrm{ml}$ deney ortamı hazırlanmış ve her deney kabı için 10 adet Daphnia magna kullanılmıştır. Deney süresince sıcaklık $20 \pm 2$ ${ }^{\circ} \mathrm{C}$ 'de tutulmuştur. Su özeliği Ph: 8,1, İletkenlik: 161,2 $\mu \mathrm{s} / \mathrm{cm}$, Alüminyum (Al): $26,5 \mu \mathrm{g} / \mathrm{L}$, Amonyum: N.D, Klorür (Cl): $1 \mathrm{Mg} / \mathrm{L}$, Top. Demir (Fe): $76 \mu \mathrm{g} / \mathrm{L}$, Mangan (Mn): N.D, Oksitlenebilirlik (Oxibility): $2,8 \mathrm{Mg} / \mathrm{L}$, Sülfat (So4): 1,4 Mg/L, Sodyum (Na): 6,9 Mg/L, fotoperiyot 16 saat aydınlık:8 saat karanlık şeklinde düzenlenmiştir.

Deneme; ön deney, ana deney ve $\mathrm{LC}_{50}$ nin hesaplanması olmak üzere 3 aşamada statik olarak yürütülmüştür. 24 ve 48 saatlik ön denemede seyreltme suyu kullanılarak $\% 0,01 ; \% 0,1 ; \% 1 ; \% 10$ ve $\% 100$ 'lük deney çözeltileri bulunan geniş aralıklı konsantrasyonlar hazırlanarak ana deneyde baz alınabilecek değerler tespit edilmiştir (Anonim 1990). Ana deneyde on deney sonucu logaritmik ölçekte orta nokta yaklaşım metoduna göre seçilmiş, 24 ve 48 saat içinde $\% 0$ ve \%100 ölüm görülen değerler arasında bulunan beş konsantrasyon ile bir kontrol grubu kullanılmıştır (Reish ve Oshida 1987). Deneme \% 95'lik güven sınırının belirlenmesinde her konsantrasyon için iki seri olarak yapılmıştır.

Denemede, glifosatın toksik etkisini saptamak için probit analiz yöntemi kullanılmıştır. Yöntemde ana deney sonucu saptanan konsantrasyonların ampirik probitlerle eşlenmesi ile oluşturulan probit regresyon hattından $\mathrm{LC}_{50}$ değeri hesaplanmıştır (Düzgüneş ve Düzgüneş 1958, Ünsal 1996).

\section{Bulgular ve Tartışma}

Kaynak taramasına bağlı olarak herbisit Glifosatın, Daphnia magna üzerine toksisitesine ilişkin çalışmalar son derece sınırlı olup, bu çalışmadan elde edilen bulgular ayrıca diğer türler üzerinde ve diğer kimyasallarla yapılan çalışmalarların sonuçları ile de tartışılmıştır. Daphnia'larda 24 saatlik ön deneye ilişkin sonuçlar Çizelge 4.1 de verilmiştir.

Çizelge 4.1 Daphnia'larda 24 Saatlik Ön Deney Sonuçları

\begin{tabular}{|c|c|c|c|}
\hline $\begin{array}{c}\text { Konsantrasyon } \\
\mathbf{m g} / \mathbf{L})\end{array}$ & $\begin{array}{c}\text { Daphnia } \\
\text { Sayısı }\end{array}$ & $\begin{array}{c}\text { 24 Saat } \\
\text { İcinde Ölen } \\
\text { Daphnia } \\
\text { Sayısı }\end{array}$ & Ölüm (\%) \\
\hline I.Seri & 10 & - & 0 \\
\hline Kontrol Grubu & 10 & - & 0 \\
\hline $1 / 10000$ & 10 & 10 & 100 \\
\hline $1 / 1000$ & 10 & 10 & 100 \\
\hline $1 / 100$ & 10 & 10 & 100 \\
\hline $1 / 10$ & & & \\
\hline II. Seri & 10 & - & 0 \\
\hline Kontrol Grubu & 10 & - & 0 \\
\hline $1 / 10000$ & 10 & 10 & 100 \\
\hline $1 / 1000$ & 10 & 10 & 100 \\
\hline $1 / 100$ & 10 & 10 & 100 \\
\hline $1 / 10$ & \multicolumn{3}{|c}{} \\
\hline & & & \\
\hline
\end{tabular}


Çizelge 4.1 den görüleceği gibi ön deneme sonucunda $1 / 10, \quad 1 / 100$ ve $1 / 1000$ 'lik konsantrasyonlarda tüm organizmalar ölürken (\%100) diğer konsantrasyonda (1/10000) ölüm gözlenmemiştir. Bu sonuçlar baz alınarak \%100 ölüm olan en düşük konsantrasyon 1/1000 ile ölüm görülmeyen (\%0 ölüm) en yüksek konsantrasyon olan $1 / 10000$ arasında ana deneyin konsantrasyonları belirlenmiştir.

Ön deney sonuçlarına göre "logaritmik ölçekte orta nokta ile yaklaşım metodu"na göre seçilmiş 5 konsantrasyon ile yapılmış 24 saatlik ana deney sonuçları Çizelge 4.2' de özetlenmiştir.

Ön deney sonucu elde edilen ve ana deneyde kullanılan 5 farklı doz ve 1 kontrol grubunda, 24 saat içinde öldüren glifosat konsantrasyonları 1. ve 2. seriler olmak üzere hesaplanmıştır. Daphnia'larda 48 saatlik ön deneye ilişkin sonuçlar Çizelge 4.3 de verilmiştir.

Çizelge 4.2 Daphnia'larda 24 Saatlik Ana Deney Sonuçları

\begin{tabular}{|c|c|c|c|}
\hline $\begin{array}{c}\text { Konsantrasyon } \\
\text { (mg/L) }\end{array}$ & $\begin{array}{c}\text { Daphnia } \\
\text { Sayısı }\end{array}$ & $\begin{array}{c}\text { 24 Saat } \\
\text { İçinde Ölen } \\
\text { Daphnia } \\
\text { Sayısı }\end{array}$ & $\begin{array}{c}\text { Ölüm } \\
\text { (\%) }\end{array}$ \\
\hline I. Seri & 10 & 3 & 30 \\
\hline 0,0115 & 10 & 4 & 40 \\
\hline 0,018 & 10 & 5 & 50 \\
\hline 0,021 & 10 & 7 & 70 \\
\hline 0,028 & 10 & 8 & 80 \\
\hline 0,032 & 10 & 0 & 0 \\
\hline Kontrol & 10 & & 30 \\
\hline II. Seri & 10 & 3 & 40 \\
\hline 0,0115 & 10 & 5 & 50 \\
\hline 0,018 & 10 & 8 & 80 \\
\hline 0,021 & 10 & 9 & 90 \\
\hline 0,028 & 10 & 0 & 0 \\
\hline 0,032 & & & \\
\hline Kontrol & & & \\
\hline & & & \\
\hline
\end{tabular}

Çizelge 4.3 Daphnia'larda 48 Saatlik Ön Deney Sonuçları

\begin{tabular}{|c|c|c|c|}
\hline $\begin{array}{c}\text { Konsantrasyon } \\
(\mathbf{m g} / \mathbf{L})\end{array}$ & $\begin{array}{c}\text { Daphnia } \\
\text { Sayısı }\end{array}$ & $\begin{array}{c}\text { 48 Saat } \\
\text { İçinde Ölen } \\
\text { Daphnia } \\
\text { Sayısı }\end{array}$ & $\begin{array}{c}\text { Ölüm } \\
(\%)\end{array}$ \\
\hline I.Seri & & - & 0 \\
\hline Kontrol Grubu & 10 & - & 0 \\
\hline $1 / 10000$ & 10 & 10 & 100 \\
\hline $1 / 1000$ & 10 & 10 & 100 \\
\hline $1 / 100$ & 10 & 10 & 100 \\
\hline $1 / 10$ & 10 & & \\
\hline II. Seri & & - & 0 \\
\hline Kontrol Grubu & 10 & - & 0 \\
\hline $1 / 10000$ & 10 & 10 & 100 \\
\hline $1 / 1000$ & 10 & 10 & 100 \\
\hline $1 / 100$ & 10 & 10 & 100 \\
\hline $1 / 10$ & 10 & \multicolumn{2}{|c}{} \\
\hline
\end{tabular}

Çizelge 4.3 incelendiğinde ön deneme sonucunda $1 / 10, \quad 1 / 100$ ve $1 / 1000$ 'lik konsantrasyonlarda tüm organizmalar ölürken (\%100) diğer konsantrasyonda (1/10000) ölüm gözlenmemiştir. Bu sonuçlar baz alınarak \%100 ölüm olan en düşük konsantrasyon 1/1000 ile ölüm görülmeyen (\%0 ölüm) en yüksek konsantrasyon olan 1/10000 arasında ana deneyin konsantrasyonları belirlenmiştir.

Ön deney sonuçlarına göre "logaritmik ölçekte orta nokta ile yaklaşım metodu"na göre seçilmiş 5 konsantrasyon ile yapılmış ana deney sonuçları Çizelge 4.4' de özetlenmiştir. Ön deney sonucu elde edilen ve ana deneyde kullanılan 5 farklı doz ve 1 kontrol grubunda, 48 saat içinde öldüren glifosat konsantrasyonları 1 . ve 2 . seriler olmak üzere hesaplanmıştır.

Bu çalışmada 24 ve 48 saat süreli statik olarak yapılan denemelerde $\mathrm{LC}_{50}$ değerleri; 24 saatlik sürede $0,019 \mathrm{mg} / \mathrm{L}$ (\%95 güven aralığında=0,012 mg/L $0,024 \mathrm{mg} / \mathrm{L}$ ) olarak, 48 saatlik sürede ise $0,012 \mathrm{mg} / \mathrm{L}$ (\%95 güven aralığında=0,001 $\mathrm{mg} / \mathrm{L}-0,016 \mathrm{mg} / \mathrm{L}$ ) olarak saptanmıştır. Hessen ve ark. (1994) glifosatın Daphnia pulex yavruları için 48 saatlik LC $_{50}$ değerini $0,01 \mathrm{mg} / \mathrm{L}$ olarak belirlemişlerdir. Dolayısıyla sonuçlar arasında paralellik gözlenmektedir.

Baird ve ark. (1989) laboratuarlar arası toksisite test sonuçlarının değişkenliğinde genotip ve kültürde kullanılan besinin etkilerini göstermişlerdir. Ayrıca Daphnia magna gençlerinin duyarlılığı üzerinde ebeveyn beslenmesinin önemi Enserink ve ark. (1990) tarafından da bildirilmektedir.

Çeşitli pestisitlerin Daphnia türleri üzerinde etkileri araştırımıştır. İki herbisit olan paraquat ve

Çizelge 4.4 Daphnia'larda 48 Saatlik Ana Deney Sonuçları

\begin{tabular}{|c|c|c|c|}
\hline $\begin{array}{c}\text { Konsantrasyon } \\
\text { (mg/L) }\end{array}$ & $\begin{array}{c}\text { Daphnia } \\
\text { Sayısı }\end{array}$ & $\begin{array}{c}\text { 48 Saat } \\
\text { İçinde Ölen } \\
\text { Daphnia } \\
\text { Sayısı }\end{array}$ & $\begin{array}{c}\text { Ölüm } \\
(\%)\end{array}$ \\
\hline I. Seri & & 5 & $\% 50$ \\
\hline 0,0115 & 10 & 7 & $\% 70$ \\
\hline 0,018 & 10 & 8 & $\% 80$ \\
\hline 0,021 & 10 & 8 & $\% 80$ \\
\hline 0,028 & 10 & 9 & $\% 90$ \\
\hline 0,032 & 10 & 0 & $\% 0$ \\
\hline Kontrol & 10 & 5 & $\% 50$ \\
\hline II. Seri & & 7 & $\% 70$ \\
\hline 0,0115 & 10 & 8 & $\% 80$ \\
\hline 0,018 & 10 & 9 & $\% 90$ \\
\hline 0,021 & 10 & 10 & $\% 100$ \\
\hline 0,028 & 10 & 0 & $\% 0$ \\
\hline 0,032 & 10 & \multicolumn{3}{|c}{} \\
\hline Kontrol & 10 & & \\
\hline & & & \\
\hline
\end{tabular}


glifosatın ticari formları, D. spinulata üzerinde, $\% 50$ etki konsantrasyon değerleri Alberdi ve ark. (1996) tarafından araştırılmıştır. Paraquat için $\mathrm{EC}_{50}$ değerleri 24 ve 48 saat süreli deneylerde sırasıyla 9,91-2,57 $\mathrm{mg} / \mathrm{L}$, glifosat için ise 94,87-66,18 mg/L olarak bulunmuştur. $D$. obtusa'da carbarylin $\mathrm{EC}_{50}$ değeri 0,015-0,115 $\mathrm{mg} / \mathrm{L}$, paraquatın $\mathrm{EC}_{50}$ değeri $>70-8,7$ $\mathrm{mg} / \mathrm{L}$ (Gustavo ve ark. 1996) olarak belirlenmiştir.

Organik fosforlu pestisitlerin, organizmalar üzerindeki toksik etkileri asetil kolin esteraz enziminin engellenmesiyle gerçekleştiği bilinmektedir. $D$. magna'da asetil kolin esteraz enziminin engellenmesi, Lillius ve ark. (1994), Ankley ve ark. (1991) tarafından gösterilmiştir.

Abdelghani ve ark. (1997) Roundup'un 96 saatlik $\mathrm{LC}_{50}$ değerini, kanal yayınında (Ictalurus punctatus) 14,5 ppm, mavi solungaçlı güneş balığında (Lepomis michochirus) 13 ppm ve kerevitlerde yaklaşık 64000 ppm olarak bildirmişlerdir. Daphnia pulex için 96 saatlik $\mathrm{EC}_{50}$ değeri $25,5 \mathrm{mg} / \mathrm{L}$ olarak hesaplanmıştır (Servizi ve ark. 1987). Yapılan başka bir çalışmada ise, Roundup'un Daphnia pulex için 48 saatlik $\mathrm{EC}_{50}$ değeri $7,9 \mathrm{mg}$ glifosat/L olarak bulunmuştur (Hartman ve Martin 1984). Yapılan çalışmalar D. magna'nın daha duyarlı olduğuna ve Daphnia toksisite denemelerinin önemine dikkat çekmektedir.

Denememiz sırasında glifosat uygulamaları Daphnia'ların hareketlerinde bir yavaşlamaya neden olmuştur. Ölmeden önce bireyler dibe ve yüzeye doğru birkaç kez yüzdükten sonra kabın dibine doğru giderek vücutlarında titreme hareketleri göstermişlerdir.

Dodson ve Hanazato (1995), D. magna'nın Carbaryl'e karşı toksik tepkisini gösteren üç tip davranış belirlemişlerdir. Birinci tip, kendi etrafında dönerek yün eğirme hareketi, ikincisi stresli titreme, üçüncüsü ise hareket etmeden sinme davranışlarıdır. Her üç tip davranış, çalışmamızda glifosata karşı tepkide de gözlenmiştir. Yüksek konsantrasyonlarda birinci, düşük konsantrasyonlarda ise ikinci tip davranış sergilenmiştir.

\section{Sonuç}

Bu çalışmada Daphnia magna üzerine herbisit glifosatın akut toksisitesi ( $\left.\mathrm{LC}_{50}\right) 24$ saatlik sürede 0,019 $\mathrm{mg} / \mathrm{L}, 48$ saatlik sürede ise $0,012 \mathrm{mg} / \mathrm{L}$ olarak saptanmıştır. Elde edilen bulgular, bu herbisitin $D$. magna üzerine etkilerini ortaya koyması yanında, akvatik canlılar üzerindeki toksisitesine ilişkin veri tabanının genişletilmesine katkıda bulunması açısından da önemli olacaktır. Ayrıca su ekosistemlerinin korunmasında, bu maddelerin kullanımına sınırlamalar getirilmesi açısından da büyük önem taşımaktadır.

\section{Kaynaklar}

Abdelghani, A. A., P. B. Tchounwou, A. C. Anderson, H. Sujono, L. R. Heyer and A. Monkiedje. 1997. Toxicity evaluation of single and chemical mixtures of Roundup,Garlon 3A, 2,4-D, and syndets surfactant to channel catfish (Ictalurus punctatus), bluegill sunfish (Lepomis michochirus), and crawfish. Environmental Toxicology and Water Quality 12(3): 237-243.

Alberdi, J. L., M. E. Saenz, W.D. Di Marzio and M. C. Tortorelli. 1996. Comparative acute toxicity of two herbicides, paraquat and glyphosate to Daphnia magna and D.spinulata. Bulletin of Environmental Contamination and Toxicology 57: 229-235.

Ankley, G.T., J. R Dierkes and D. A. Jensen. 1991. Piperonyl butoxide as a tool in aquatic toxilogical research with organophosphate insecticides. Ecotoxicology and Environmental Safety 21: 266-274.

Anonim. 1990. Endüstriyel Sıvı Atıklar ve Atiksular-Akut Zehirlilik Deneyleri-Canlılık Deney Metodları. TS 8264.

Baird, D. D., R. P. Upchurch, W. B. Homesley and J. E. Franz. 1971. Introduction of new broad spectrum postemergence herbicide class with utility for herbaceous perennial weed control. Proceeding of the 26 th North Central Control Conferance, 64-68. (Kansas City, USA, 7-9. December 1971).

Baird, D. J., I. Barber, M. Bradly, P. Calow and A. M. V. M. Soares. 1989. The Daphnia bioassay: A critique Hydrobiologia 188/189:403-406.

Bronstad, J.O. and H.O. Friestad. 1985. Behavior of glyphosate in the aquatic environment. In E. Grossbard and D. Atkinson (eds), The herbicide glyphosate. Butterworths, London, p 200-205.

Dodson, S.I. and T. Hanazato. 1995. Commentary on effects of anthropogenic and natural organic chemicals on development, swimming behavior and reproduction of Daphnia, a key member of aquatic ecosystems. Environmental Health Perspectives 103: 7-11.

Düzgüneş, Z. ve O. Düzgüneş. 1958. Entomolojide istatistik metotlar. A. Ü. Ziraat Fakültesi yayınları no.140,1-48, Ankara.

Enserink, L., W. Luttmer and H. Maas-Diepeveen. 1990. Reproductive strategy of Daphnia magna affects the sensitivity of its progeny in acute toxicity tests. Aquatic Toxicology 17: 15-26.

Goldsborough, L.G. and A.E. Beck. 1989. Rapid dissipation of glyphosate in small forest ponds. Archives of Environmental Contamination and Toxicology 18: 537544.

Gustavo,D., B. Rossini and A. E. Ronco. 1996. Acute toxicity bioassay using Daphnia obtusa as a test organism. Environmental Toxicology and Water Quality: An International Journal 11: 255-258. 
Hanazato, T. 2001. Pesticide effects on freshwater zooplankton: an ecological perspective. Environmental Pollution 112 (1): 1-10.

Hartman, W. A. and D. B. Martin. 1984. Effect of suspended bentonite clay on the acute toxicity of glyphosate to Daphnia pulex and Lemna minor. Bulletin of Environmental Contamination and Toxicology 33: 355361.

IARC 1977. Monographa on the Evaluatin of the Carcinogenic Risk of Chemical to Man. International Agency for Research on Cancer Val: 15, Lyon.

Knuuttila, P. and H. Knuuttila. 1979. The crystal and molecular structure of N-Phosphonomethyl glycine (Glifosat). Acta Chemica Scandinavia B 33: 623-626.

Lilius, H., B. Isomaa and T. Holmström. 1994. A comparison of the toxicity of 50 reference chemicals to freshly isolated rainbow trout hepatocytes and Daphnia magna. Aquatic Toxicology 30: 47-60.

Medina, H.S.G., M. E. Lopata and M. Bacila. 1994. The response of sea-urchin egg embryogenesis towards the effect of some pesticides. Arquivos de Biologia Tecnologia 37 (4): 895-906.

Monsanto, C. 1980. Toxicology and Environmental Review. Roundup Herbicide Bulletin 1: 1-3.
Persoone, G. and C. R. Janssen. 1993. Fresh water invertebrate toxicity tests. In: Hand book of ecotoxicology. Ed. by P. Calow. Blackwell Sci. Pub. Newyork, 1, 51-53.

Piska, M. B. and S. Waghray. 1997. Toxic effects of dimethoate on primary production of lake ecosystem. Indian Journal of Environmental Health 33(1): 126-127.

Reish, D. L. and P. S. Oshida. 1987. Manual of Methods in Aquatic Environment Research. Part 10. Short-Term Static Bioassays. FAO Fisheries Technical Paper 247: 17-33.

Servizi, J. A., R. W. Gordon, and D. W. Martens. 1987. Acute toxicity of Garlon 4 and Roundup herbicides to salmon, daphnia and trout. Bulletin Environmental Contamination Toxicology 39: 15-22.

Ünsal, M. 1996. Kirlilik Deneyleri- Yöntemler ve Sonuçların Değerlendirilmesi. ODTÜ Deniz Bilimleri Enstitüsü 7779, 120-142. Erdemli/Mersin.

\section{İletişim Adresi:}

Süleyman BEKCAN

Ankara Üniversitesi Ziraat Fakültesi

Su Ürünleri Bölümü -Ankara

Tel: 03125961645

E-posta:bekcan@agri.ankara.edu.tr 